\title{
Solvent-Free Conjugated Polymer Fluids with Optical Functions
}

\author{
Akira Shinohara ${ }^{a}$ (D) \\ Zhenfeng Guo ${ }^{\mathrm{a}, \mathrm{b}}$ (D) \\ Chengjun Pan ${ }^{a}$ (iD) \\ Takashi Nakanishi*a,b,c (D) \\ a Shenzhen Key Laboratory of Polymer Science and Technology, College of Materials \\ Science and Engineering, Shenzhen University, 1066 Xueyuan Boulevard, Nanshan, \\ Shenzhen 518055, China \\ ${ }^{\mathrm{b}}$ Division of Soft Matter, Graduate School of Life Science, Hokkaido University, Kita 10, \\ Nishi 8, Kita-ku, Sapporo 060-0810, Japan \\ 'International Center for Materials Nanoarchitectonics (WPI-MANA), National Institute \\ for Materials Science (NIMS), 1-1 Namiki, Tsukuba 305-0044, Japan \\ nakanishi.takashi@nims.go.jp
}

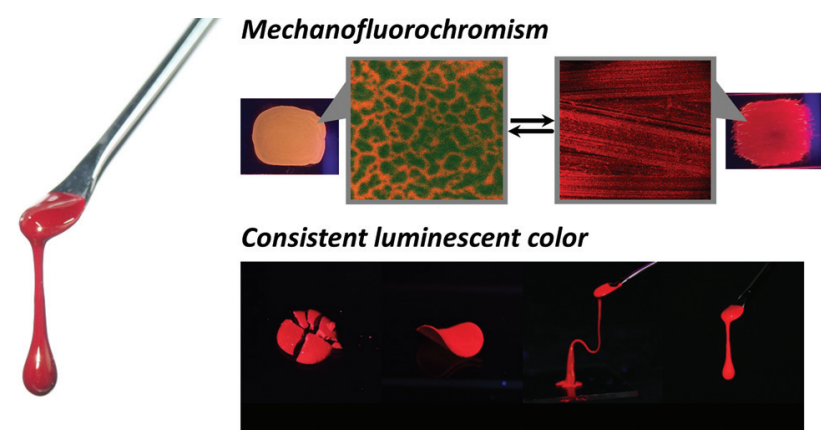

density of the functional unit, as well as the fundamental curiosity about the structural requirements for fluidity, intrinsic single-component fluidic materials remain worthwhile targets. Liquid crystals (LCs) are the longest-studied functional fluidic materials, which form highly ordered supramolecular self-assembled structure. Semiconducting LCs have common molecular architecture: rigid $\pi$-conjugated units with soft side chains. Over the last decade, our group ${ }^{1-9}$ and many others ${ }^{10-23}$ have inherited this molecular design concept and focused not only on the highly ordered, supramolecular self-assembled structure, but also on the disordered and fluid properties under precisely controlled intermolecular interactions.

Since conjugated polymers (CPs) have a longer conjugation length than their monomeric equivalents, they exhibit unique optoelectronic properties such as metallic conductivity and carrier transportability. ${ }^{24,25}$ When considering this class of material as a solvent-free fluid, it is also expected to possess a variety of functions as a soft polymer. Fluidic polymers exhibit deformation dynamics that are substantially different from those of small molecular fluids. $^{26}$ For example, polymers concurrently possess viscosity (fluidity) and elasticity, namely, viscoelasticity. However, fluidification of CPs is more challenging due to the enhanced intermolecular cohesive forces (e.g., $\pi-\pi$ interaction). In light of these factors, and despite CPs being promising candidates for stretchable electronics, studies on their viscoelasticity are limited compared to those on the mature physics of commodity polymers.

Polymer design approaches to promote the deformability of CPs can be classified into three types with respect to their chemical structure (Figure 1): insertion of flexible spacers into the conjugated backbone (Type I) ${ }^{27,28}$; block $^{29-32}$ or graft copolymerization ${ }^{33,34}$ with a soft polymer (Type II); internal plasticization by small molecular side chains maintaining full conjugation of the polymer backbone (Type III) (this review). Type I and II CPs are the most well studied for controlling the crystallinity to maintain the electrical properties. ${ }^{35}$ The Type I approach 


\section{Biosketches}
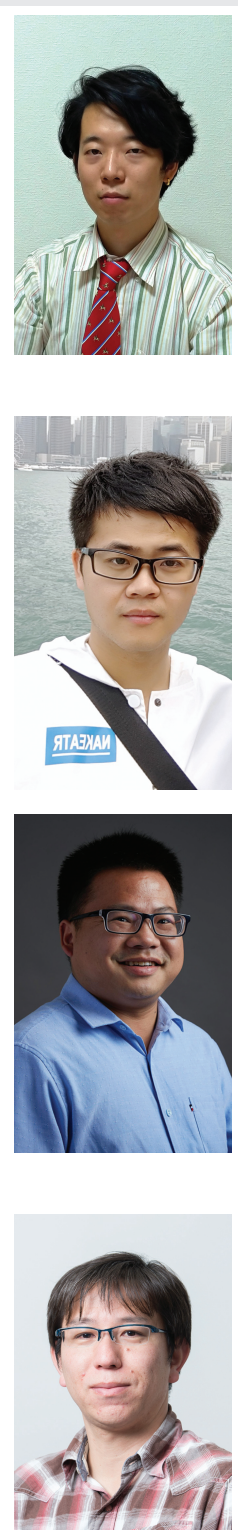

Akira Shinohara obtained his PhD degree in 2017 from the University of Yamanashi, Japan, under the supervision of Prof. Hideyuki Shinmori. His doctoral research focused on the design and investigation of photodynamic functions of porphyrin-gold nanoparticle composites. At present, he is a postdoctoral researcher in the research team of Prof. Lei Wang at
Shenzhen University, China, where he has been working since 2017. His current research involves investigating and understanding solvent-free functional polymer fluids.
Chengjun Pan received his $\mathrm{PhD}$ degree in 2014 from the University of Tsukuba, Japan, under the supervision of Prof. Masayuki Takeuchi and Prof. Kazunori Sugiyasu. In the same year, he joined the Organic Materials a joint-graduate school program of National Institute for Materials Science (NIMS) and Hokkaido University, Japan.
Group, NIMS, as a postdoctoral researcher. Since 2015, he has been working at Shenzhen University as an assistant professor, and he was promoted as an associate professor in 2019. His current research interest focuses on the design and creation of functional conjugated polymers with unique optical, electronic, and mechanical properties. is also widely used for highly crystalline non-CPs such as polyimides, known as super engineering plastics e.g., Kapton $^{\circledR}$ having oxygen atoms as flexible spacers). In CPs, however, not only the mechanical properties but also the rigid conjugated backbone is deeply involved in the optoelectronic properties. Therefore, breaking the $\pi$-conjugation is usually considered detrimental to the optoelectronic properties. In addition, there is no guarantee that the softness and the desired conjugation length will be compatible. Thus, Type II appears to be the only conceivable approach to achieve compatibly demanded optoelectronic properties and deformability.
Takashi Nakanishi received his $\mathrm{PhD}$ degree in a shorter period from . Thereaf at Houston University, United States, and at Oxford University, United Kingdom, and joined NIMS, Japan, in 2004. Since 2016, he has held the position of a group leader at MANA,
NIMS. In 2007-2010, he was also a group leader at the Max Planck Institute of Colloids and Interfaces, Germany, and in 2007-2011, he was a researcher of PRESTO, Japan Science and Technology Agency. He also has several visiting professor experiences at Warsaw University of Technology in Poland, Institute for Molecular Science in Japan, Hokkaido University in Japan, The University of Tokyo in Japan, and Shenzhen University in China. His research interest focuses on functional organic soft materials with precisely controlled self-assembly, in particular non-assembled functional molecular liquids, and their optoelectronic functions.
Molecular design philosophy of Type III CPs is inherently the same as that of traditional LCs where weak intermolecular interactions are carefully controlled. While softness has been pursued, less attention has been paid to the fluidification and fluidity of CPs. This is likely due to the fact that they are densely covered with insulating side chains, thus their optical functions are rather emphasized than inhibited electrical conductivity. There are excellent reviews on the structure-property relationships of Type I and II CPs. ${ }^{36,37}$ In this short review, we provide a concise overview and describe future prospects of fluidic Type III CPs. 


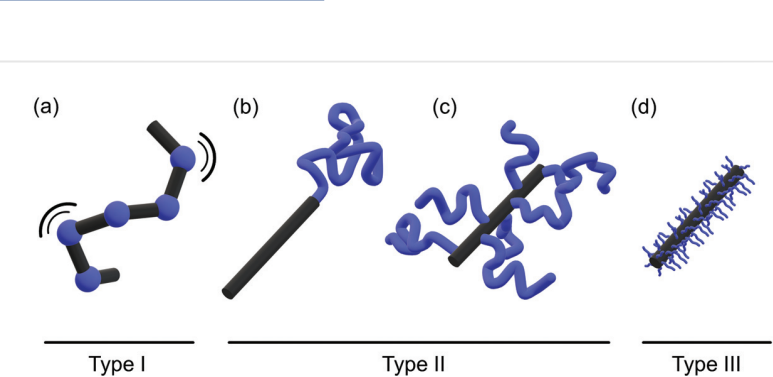

Figure 1 Polymer design approaches to endow CPs with fluidity. Thick black bar: conjugated polymer backbone (a) insertion of flexible spacers (blue spheres) (Type I); (b) block and (c) graft copolymerization (Type II). Blue segments indicate flexible polymer block/graft; (d) internal plasticization by small molecular side chains (thin blue chains) (Type III, this review).

\section{Polymer Design}

\subsection{Fluidity of Polymeric Materials ${ }^{26}$}

Unlike most small molecular fluids, polymeric fluids exhibit complex fluidity (i.e., viscoelasticity) that is strongly dependent on the deformation time scale. At a constant temperature, viscoelastic materials show fluidic behavior under slow deformation, whereas they exhibit stiffer behavior (rubbery and glassy) under fast deformation (Figure 2). ${ }^{38}$ The famous pitch drop experiment is a good example of this time-scale-dependent behavior. ${ }^{39}$ Coal pitch flows over a time scale of years but it can be easily shattered when hit with a hammer, showing stiff, glassy solid features. It is therefore necessary to define 'fluid' with a specific

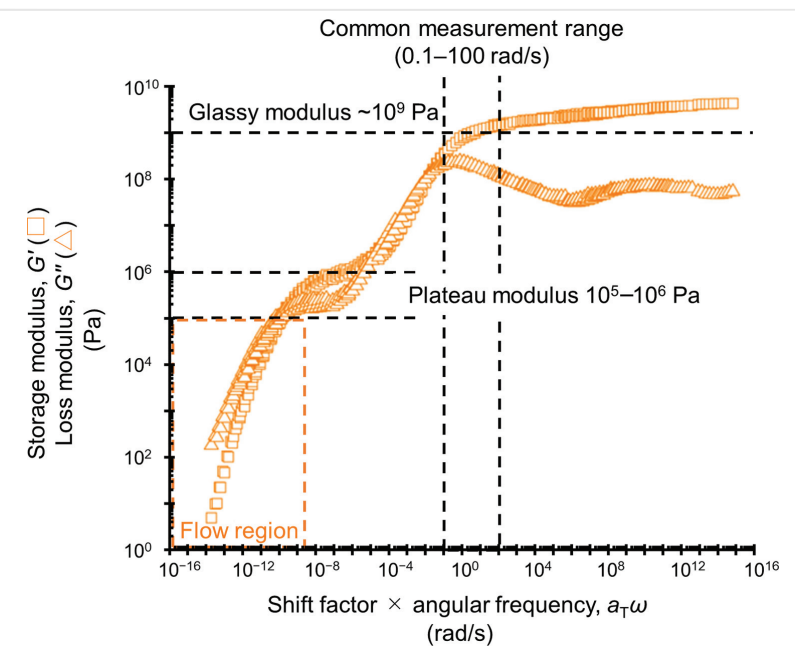

Figure 2 Rheologicalspectrum of regiorandom poly(3-hexylthiophene) as a typical example (reference temperature $=0{ }^{\circ} \mathrm{C}$ ). A sharp drop of moduli at $a_{\mathrm{T}} \omega \sim 10^{-1} \mathrm{rad} / \mathrm{s}$ indicates glass transition. Reprinted with permission from Ref. 38. Copyright 2017 American Chemical Society. deformation time scale as well as at a specific temperature. Frequency-dependent fluidic properties of polymers are routinely measured by dynamic mechanical analysis and oscillatory shear rheometry (often referred to simply as 'rheology'). The latter technique is preferably used for soft/fluidic materials. The response of the polymer to the sinusoidal oscillatory shear strain can be characterized by two moduli, namely, the storage (elastic) modulus $\left(G^{\prime}\right)$ and the loss (viscous) modulus $\left(G^{\prime \prime}\right)$, respectively.

Polymers can be broadly divided into two classes: crystalline and amorphous. Amorphous polymers begin to flow above their glass transition temperature $\left(T_{\mathrm{g}}\right)$. Although $G^{\prime} \gg G^{\prime \prime}$ in the glass state (with a typical glassy modulus of $G^{\prime} \cong 10^{9} \mathrm{~Pa}$ ), a crossover and a sharp drop in both moduli are observed in this region. In thermal measurements, the corresponding signature is observed as a jump in the heat capacity. Amorphous polymers essentially exhibit only one phase transition (i.e., glass transition), whereas crystalline polymers exhibit multiple phase transitions and complex thermomechanical behavior owing to strong intermolecular interactions. Another consideration in terms of fluidity common to crystalline/amorphous polymers is entanglement. When the polymer exceeds a certain length (degree of polymerization), it becomes entangled and its viscosity increases with higher-order scaling. In thermomechanical measurements, an entanglement plateau region is observed, where $G^{\prime}$ is $10^{5}-10^{6} \mathrm{~Pa}$ (plateau modulus), and is almost independent of the deformation frequency.

As mentioned above, the fluidity of polymers is complicated. In this review, CP fluid (CPF) is defined as satisfying the following criteria: first, $T_{\mathrm{g}}$ is lower than room temperature $\left(25{ }^{\circ} \mathrm{C}\right)$. Second, in the general deformation frequency measurement (typically $0.1-100 \mathrm{rad} / \mathrm{s}$ ), there is a linear viscoelastic region where $G^{\prime}$ is smaller than $G^{\prime \prime}$ and below $\sim 10^{5} \mathrm{~Pa}$.

\subsection{Type III CPs with $T_{g}<25{ }^{\circ} \mathrm{C}$}

When compared to Type I and II CPs, the chemical structural feature of Type III CPs is that they rely solely on the small molecular side chains for their softness. Note that graft copolymers or CPs with polymeric side chains are classified here as Type II. Type III CPs with a $T_{\mathrm{g}}$ below room temperature are listed in Figure 3 and Table 1 . The most typical example is a series of poly(3-n-alkylthiophene)s (P3nATs; 1-8)..$^{38,40,41}$ Poly(3-butylthiophene) has a $T_{g}$ higher than room temperature, whereas P3nATs with side chains longer than the hexyl group have a $T_{\mathrm{g}}$ below room temperature. It is noteworthy that the regioregularity is almost independent of $T_{\mathrm{g}}$ but it has a large influence on their mechanical properties. Regioregular (refers to 'consist entirely of head-to-tail repeating units') P3nATs show pseudo-rubbery thermomechanical features due to their 

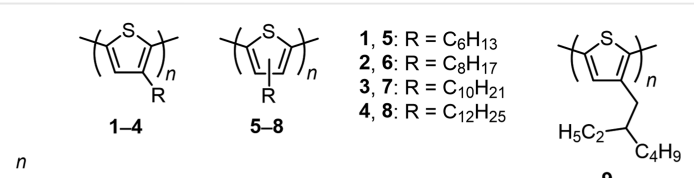<smiles>Cc1cc2sc(-c3cc(CN)c(-c4sc(C(F)(F)F)cc4C)s3)cc2s1</smiles><smiles>CCC(C)(C)c1ccc(I)cc1-c1ccc(I)cc1</smiles>

9

10

11

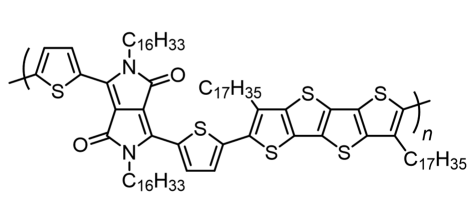

12

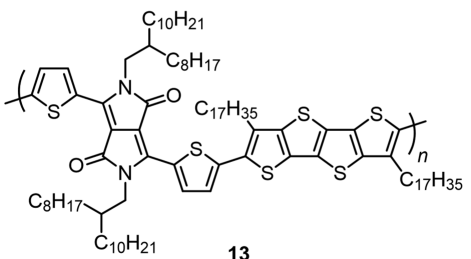

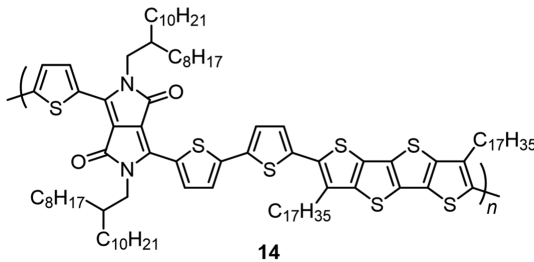

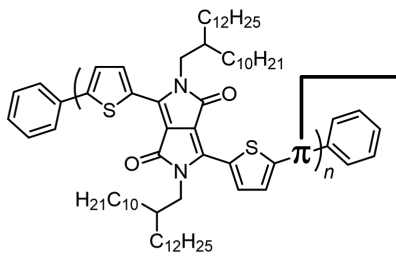

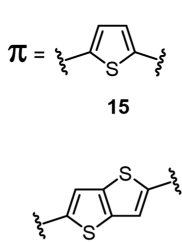

18<smiles>[Y]c1ccc(-c2ccc(C(C)(C)C)s2)s1</smiles>

16<smiles></smiles>

19

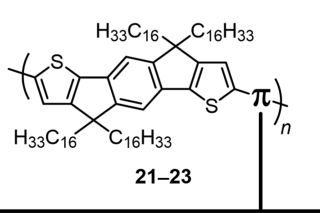

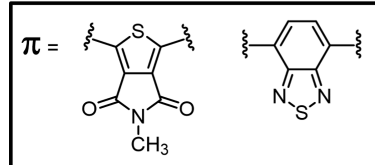
21<smiles>C/C=C\c1c(OCC(C)C)c(OCC(C)C)c(C)c(OCC(C)C)c1OCC(C)C</smiles>

29

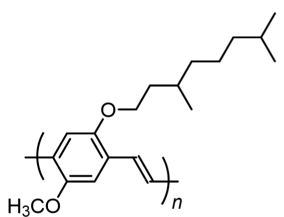

30

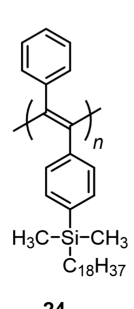<smiles>CC(=C(C)c1cccc(C(C)(C)C)c1)c1ccccc1</smiles>

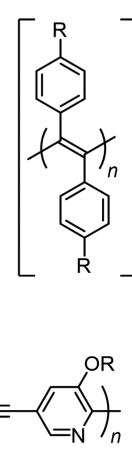

31<smiles>[R]Oc1cc(C(F)(F)F)c([R20])cc1C#Cc1ncc(C#CC)cc1OCC(=O)OCC</smiles>

33<smiles>[R]Oc1ccc(O)c(C#Cc2ncc(C#CC)cc2O)c1</smiles>

32<smiles>[R]Oc1ccc(O)cc1C#Cc1ncc(C#CC)cc1OCC(N)=O</smiles>

34

Figure 3 Chemical structures of Type III CPs (1-34), which possess $T_{\mathrm{g}}<25^{\circ} \mathrm{C}$.

high crystallinity, whereas regiorandom P3nATs behave similarly to amorphous polymers due to their low crystallinity. Regioregular polythiophene substituted with a 2ethylhexyl chain possesses a $T_{\mathrm{g}}$ nearly at room temperature, depending on its molecular weight $(\mathbf{9}) .{ }^{42}$ Gomez and coworkers found a universal rule for $T_{\mathrm{g}}$ of Type III CPs, focusing on the difference in the rotational barriers between 5- and 6-membered rings in polymers. ${ }^{41}$ They explained that thiophene-rich polymers such as $\mathbf{1 0}$, which possess low rotational barriers, tend to have a lower $T_{\mathrm{g}}$ compared to that of polymers with large rotational barriers. However, polyfluorenes, which are classified as high $T_{\mathrm{g}}$ polymers, can also have a $T_{\mathrm{g}}$ below room temperature by introducing long side chains (11).

Diketopyrrolopyrrole (DPP)-based polymers (12-20), well-known as high-performance organic semiconductors, can easily introduce alkyl chains into nitrogen atoms, making it easy to adjust $T_{\mathrm{g} .}{ }^{43-45}$ Indacenodithiophene-based polymers substituted with long alkyl chains (21-23) also have a low $T_{\mathrm{g} .}{ }^{46,47}$ Note that all of these polymers have a $G^{\prime}$ of about $10^{8} \mathrm{~Pa}$. As mentioned in the Introduction, Type III CPs do not appear to be a very attractive material in terms of 
Table 1 Thermal and mechanical properties of Type III CPs (1-34) in Figure 1

\begin{tabular}{|c|c|c|c|c|c|c|c|}
\hline \multirow[t]{2}{*}{ Polymer } & \multicolumn{2}{|l|}{ Molecular weight } & \multicolumn{2}{|c|}{ Glass transition temperature } & \multicolumn{2}{|l|}{ Elastic modulus } & \multirow[t]{2}{*}{ Ref. } \\
\hline & $M_{\mathrm{n}}(\mathrm{Da})^{\mathrm{a}}$ & $\mathrm{PDI}^{\mathrm{b}}$ & $T_{\mathrm{g}}\left({ }^{\circ} \mathrm{C}\right)$ & Method $^{c}$ & $G^{\prime}(\mathrm{Pa})$ & Method $^{d}$ & \\
\hline 1 & $3.7 \times 10^{4}$ & 1.83 & 14 & Rheo & $1.0 \times 10^{8}$ & Rheo & 38,41 \\
\hline 2 & $2.3 \times 10^{4}$ & - & -17 & Rheo & $2.5 \times 10^{7}$ & Rheo & 41 \\
\hline 3 & $4.8 \times 10^{4}$ & - & -27 & Rheo & $<1.5 \times 10^{7}$ & Rheo & 41 \\
\hline 4 & $4.5 \times 10^{4}$ & - & -18 & Rheo & $2.0 \times 10^{7}$ & Rheo & 41 \\
\hline 5 & $4.2 \times 10^{4}$ & 2.41 & 4 & Rheo & $3.0 \times 10^{6}$ & Rheo & 38,41 \\
\hline 6 & $2.3 \times 10^{4}$ & - & -19 & Rheo & $3.0 \times 10^{5}$ & Rheo & 41 \\
\hline 7 & $2.5 \times 10^{4}$ & 3.0 & -25 & Rheo & - & - & 40 \\
\hline 8 & $4.6 \times 10^{4}$ & - & -30 & Rheo & $<3.0 \times 10^{5}$ & Rheo & 41 \\
\hline \multirow[t]{2}{*}{9} & $1.1 \times 10^{4}$ & 1.4 & 24 & DMA & $1.0 \times 10^{8}\left(E^{\prime \prime}\right)^{\mathrm{e}}$ & DMA & 42 \\
\hline & $2.4 \times 10^{4}$ & 1.8 & 30 & DMA & $2.0 \times 10^{8}\left(E^{\prime \prime}\right)^{\mathrm{e}}$ & DMA & 42 \\
\hline 10 & $1.7 \times 10^{4}$ & - & 5 & Rheo & $2.0 \times 10^{7}$ & Rheo & 41 \\
\hline 11 & $3.4 \times 10^{4}$ & - & 17 & Rheo & $5.0 \times 10^{7}$ & Rheo & 41 \\
\hline 12 & $4.4 \times 10^{4}$ & 1.9 & 4 & DMA & $4.4 \times 10^{8}$ & $\mathrm{BM}$ & 43 \\
\hline 13 & $3.3 \times 10^{4}$ & 1.8 & -48 & DMA & $2.4 \times 10^{8}$ & BM & 43 \\
\hline 14 & $5.0 \times 10^{4}$ & 1.7 & -48 & DMA & $8.2 \times 10^{7}$ & $\mathrm{BM}$ & 43 \\
\hline 15 & $4.7 \times 10^{4}$ & 2.83 & -4 & DMA & $1.7 \times 10^{8}$ & DMA & 44 \\
\hline 16 & $4.4 \times 10^{4}$ & 3.96 & 12 & DMA & $2.8 \times 10^{8}$ & DMA & 44 \\
\hline 17 & $2.7 \times 10^{4}$ & 3.18 & 19 & DMA & $3.2 \times 10^{8}$ & DMA & 44 \\
\hline 18 & $5.1 \times 10^{4}$ & 3.62 & 3 & DMA & $4.0 \times 10^{8}$ & DMA & 44 \\
\hline 19 & $2.6 \times 10^{4}$ & 3.69 & 4 & DMA & $4.8 \times 10^{8}$ & DMA & 44 \\
\hline 20 & $4.7 \times 10^{4}$ & 2.1 & 24 & $\mathrm{ACCC}$ & $1.7 \times 10^{8}$ & $\mathrm{BM}$ & 45 \\
\hline 21 & $1.4 \times 10^{4}$ & 1.6 & -1 & DSC & $1.1-4.1 \times 10^{8}$ & BM & 46 \\
\hline \multirow[t]{2}{*}{22} & $1.5 \times 10^{4}$ & 1.7 & 18 & DSC & $1.5-3.6 \times 10^{8}$ & $\mathrm{BM}$ & 46 \\
\hline & $9.0 \times 10^{3}$ & 1.6 & 10 & DSC & - & - & 47 \\
\hline \multirow[t]{2}{*}{23} & $1.5 \times 10^{4}$ & 1.7 & -8 & DSC & $0.8-4.0 \times 10^{8}$ & BM & 46 \\
\hline & $2.9 \times 10^{4}$ & 1.8 & 8 & DSC & - & - & 47 \\
\hline 24 & $6.6 \times 10^{5}$ & 1.31 & $\begin{array}{l}-3 \\
-6\end{array}$ & $\begin{array}{l}\text { DSC } \\
\text { DMA }\end{array}$ & $3.3 \times 10^{7}$ & DMA & 48 \\
\hline 25 & $4.9 \times 10^{5}$ & 1.63 & $\begin{array}{l}-1 \\
-9\end{array}$ & $\begin{array}{l}\text { DSC } \\
\text { DMA }\end{array}$ & $2.5 \times 10^{6}$ & DMA & 48 \\
\hline 26 & - & - & 13 & DSC & (Rubber) & - & 49 \\
\hline 27 & - & - & 14 & DSC & (Rubber) & - & 49 \\
\hline 28 & - & - & 6 & DSC & (Rubber) & - & 49 \\
\hline \multirow[t]{2}{*}{29} & $\begin{array}{l}2.2 \times 10^{4}(65 \%) \\
1.0 \times 10^{3}(35 \%)\end{array}$ & $\begin{array}{l}2.5 \\
1.1\end{array}$ & - & - & (Sticky oil) & - & 51 \\
\hline & $1.6 \times 10^{4}$ & 3.9 & 159 & DSC & (Solid) & - & 52 \\
\hline \multirow[t]{2}{*}{30} & $1.1 \times 10^{5}$ & 16.7 & 18 & DSC & - & - & 54 \\
\hline & $1.2 \times 10^{5}$ & 3.2 & 50 & DSC & - & - & 55 \\
\hline 31 & $1.4 \times 10^{4}$ & 3.1 & - & - & (Liquid) & - & 56 \\
\hline 32 & $1.5 \times 10^{4}$ & 2.7 & - & - & (Liquid) & - & 56 \\
\hline 33 & $1.4 \times 10^{4}$ & 2.4 & - & - & (Liquid) & - & 56 \\
\hline 34 & $1.4 \times 10^{4}$ & 2.4 & - & - & (Liquid) & - & 56 \\
\hline
\end{tabular}

${ }^{a}$ Number-averaged molecular weight.

bolydispersity index $=M_{\mathrm{w}} / M_{\mathrm{n}}\left(M_{\mathrm{w}}\right.$ : weight-averaged molecular weight).

CRheo: rheology; DMA: dynamic mechanical analysis; ACCC: AC chip calorimetry; DSC: differential scanning calorimetry.

${ }^{\mathrm{d}} \mathrm{BM}$ : buckling metrology.

${ }^{\mathrm{e}} \mathrm{E}^{\prime \prime}$ : tensile loss modulus. 
their electrical properties. It is widely believed that the electrical properties (e.g., electrical conductivity) and softness have a trade-off relationship. Softer DPP polymers have not yet been reported in these systems.

The earliest studies focusing on the softness rather than the electrical properties of Type III CPs may be those by Kwak et al. ${ }^{48-50}$ They reported rubber-like mechanical properties in poly(diphenylacetylene)s with two different types of side chains: alkyl silane (24 and 25) and a polyelectrolyte sulfonic acid with alkylammonium counter cations (26-28). A detailed thermomechanical characterization has not been reported, but such CPs likely have a $G^{\prime}$ of about $10^{5}-10^{6} \mathrm{~Pa}$ corresponding to the rubbery state.

Despite having a $T_{\mathrm{g}}$ below room temperature, none of the above Type III CPs meet the CPF requirements. Some reports have declared Type III CPs as a 'fluid', but did not provide detailed thermomechanical characterization. Poly( $p$-phenylene vinylene) (PPV) $\mathbf{2 9}$ was reported independently by Vanderzande and coworkers, and Suh and coworkers. ${ }^{51,52}$ The former was reported as a fluid and the latter as a fibrous solid. PPV is synthesized by the Gilch method, in which radical polymerization and anionic polymerization compete with each other, resulting in a bimodal molecular weight distribution. ${ }^{53}$ The fluid properties may be due to lowmolecular-weight fractions, suggesting that the high-molecular-weight fraction is solids. Similar inconsistencies are also found in other PPVs (e.g., 30). ${ }^{54,55}$ Thus, when discussing intrinsic fluidic properties of $\mathrm{CPF}$, complete information about the molecular weight and its distribution is essential.

There are some alternative choices, in addition to alkyl and ionic side chains, for reducing $T_{\mathrm{g}}$ of CPs. Oligo(ethylene glycol)s are well known as low-melting-point side chains (internal plasticizers). Poly( $p$-arylene ethynylene)s substituted with branched oligoethylene glycol (31-34) are reported as room-temperature fluid. ${ }^{56}$ Oligo(dimethylsiloxane)s are also known as low-melting-point side chains. ${ }^{57,58}$ However, there do not seem to be any examples of Type III CPs with these types of side chains.

\subsection{Fluidification of Polyfluorenes ${ }^{59}$}

Our group has systematically examined the structural requirements for the fluidification of poly(dialkylfluorene)s (35-37; Figure 4a). Guerbet chains, which are asymmetric alkyl chains with the chemical formula of $-\mathrm{CH}_{2}-\mathrm{CH}$

(a)

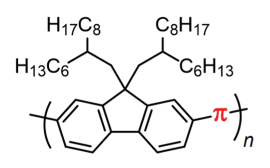

35-39
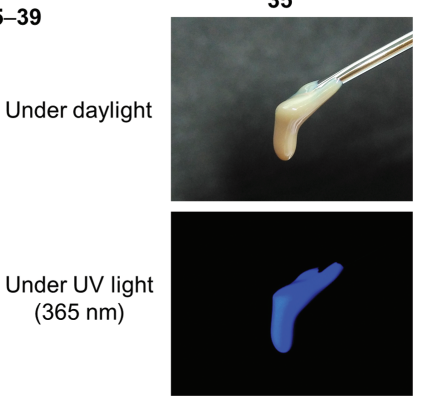

(b)
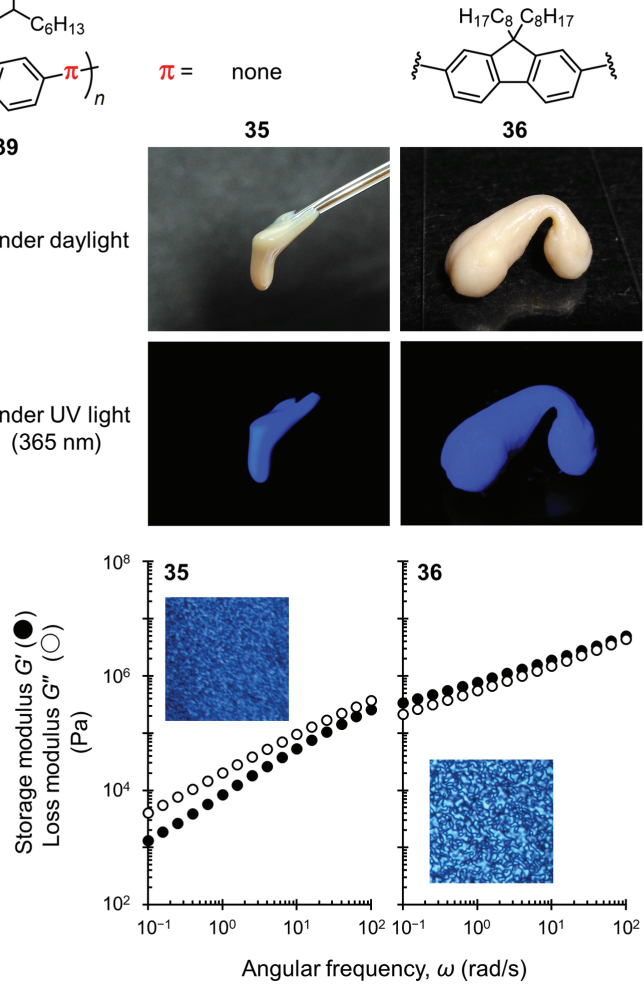

36
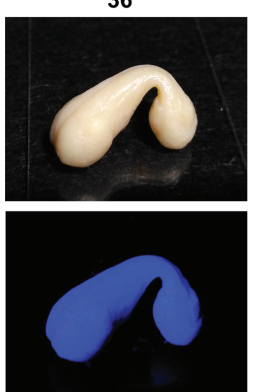
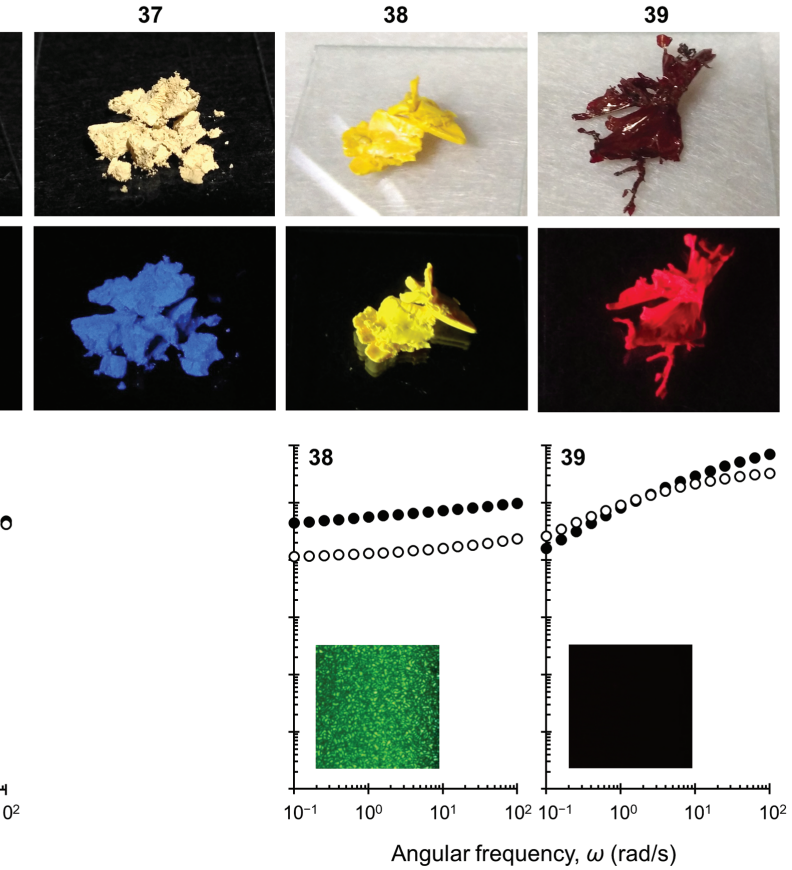

Figure 4 Polyfluorene-based Type III CPs. (a) Chemical structure and photos under daylight and UV light (365 nm). (b) Linear rheological spectra at $25^{\circ} \mathrm{C}$. Insets show microscopic images of thin-film samples under cross Nicol $\left(20 \times 20 \mu \mathrm{m}^{2}\right)$. Reprinted with permission from Ref. 59 . Copyright 2019 John Wiley. 
Table 2 Thermal and mechanical properties of Type III CPs in Refs 59 and 63

\begin{tabular}{|c|c|c|c|c|c|c|c|}
\hline \multirow[t]{2}{*}{ Polymer } & \multicolumn{2}{|c|}{ Molecular weight } & \multicolumn{2}{|c|}{ Glass transition temperature } & \multicolumn{2}{|c|}{ Elastic modulus } & \multirow[t]{2}{*}{ Ref } \\
\hline & $M_{\mathrm{n}}(\mathrm{Da})$ & PDI & $T_{\mathrm{g}}\left({ }^{\circ} \mathrm{C}\right)$ & Method $^{\mathrm{a}}$ & $G^{\prime}(\mathrm{Pa})^{\mathrm{b}}$ & Method $^{a}$ & \\
\hline 35 & $1.0 \times 10^{4}$ & 1.87 & -24 & DSC & $2.0 \times 10^{4}$ & Rheo & 59 \\
\hline 36 & $2.1 \times 10^{4}$ & 4.63 & -19 & DSC & $8.0 \times 10^{5}$ & Rheo & 59 \\
\hline 37 & $1.0 \times 10^{4}$ & 1.51 & 44 & DSC & - & Rheo & 59 \\
\hline 38 & $1.2 \times 10^{4}$ & 1.78 & -6 & DSC & $6.0 \times 10^{6}$ & Rheo & 59 \\
\hline 39 & $1.7 \times 10^{4}$ & 1.81 & 15 & DSC & $1.0 \times 10^{7}$ & Rheo & 59 \\
\hline 40 & $1.2 \times 10^{4}$ & 1.21 & 22 & DSC & $2.0 \times 10^{8}$ & Rheo & 63 \\
\hline 41 & $1.2 \times 10^{4}$ & 1.26 & -10 & DSC & $2.0 \times 10^{6}$ & Rheo & 63 \\
\hline 42 & $1.4 \times 10^{4}$ & 1.35 & -23 & DSC & $1.0 \times 10^{5}$ & Rheo & 63 \\
\hline 43 & $1.6 \times 10^{4}$ & 1.31 & -28 & DSC & $2.0 \times 10^{4}$ & Rheo & 63 \\
\hline
\end{tabular}

${ }^{\mathrm{a} D S C}$ : differential scanning calorimetry; Rheo: rheology.

${ }^{\mathrm{b}}$ At $1 \mathrm{rad} / \mathrm{s}, 25^{\circ} \mathrm{C}$.

$\left(\left(\mathrm{CH}_{2}\right)_{n} \mathrm{CH}_{3}\right)-\left(\mathrm{CH}_{2}\right)_{n+2} \mathrm{CH}_{3}$, have a much higher ability to lower the melting point (or $T_{\mathrm{g}}$ ) than the corresponding linear alkyl chains. ${ }^{60}$ Previous studies, including detailed thermal characterizations with short Guerbet chains, 2ethylhexyl groups, have shown that 2-ethylhexyl groups are inadequate for fluidifying polyfluorene. ${ }^{61}$ Using a longer Guerbet chain, a 2-hexyldecyl group, polyfluorene was found to be fluidified $\left(G^{\prime \prime}>G^{\prime}\right)$ at room temperature (35, Figure $4 \mathrm{~b}$ ). The $G^{\prime}$ of $2 \times 10^{4} \mathrm{~Pa}$ (at $\omega=1 \mathrm{rad} / \mathrm{s}$, Table 2 ) was significantly lower than previously reported for any Type III CPs and was the first well-characterized CPF.

The relationship between the viscoelasticity and the side chain structure was investigated by synthesizing alternating copolymers with different amounts of alkyl chains while maintaining the 9,9-bis(2-hexyldecyl)fluorene moiety. By removing $50 \%$ of the branches (36), the polymer was obtained as a rubbery substance and exhibited moduli of $10^{6} \mathrm{~Pa}$ with almost equal $G^{\prime}$ and $G^{\prime \prime}$ over the entire measurement frequency range. This behavior resembles that of what is known as a critical gel, ${ }^{62}$ indicating that the properties of fluid and solid are in competition. Further reduction of the alkyl chain content produced a polymer solid (37).

With the introduction of different $\pi$-conjugated units, the optical properties could be altered while maintaining the polymer deformability. The introduction of thiophene narrowed the band gap and resulted in a green luminescent polymer (38). Introducing a push-pull (donor-acceptor) structure further narrowed the band gap (39) and resulted in a red luminescent color.

All the polymers showed a different frequency dependency on their moduli from common amorphous polymer melts, except for 39, which exhibited the usual glass-toRouse transition (see Figure 2). Polymers 35, 36, and 38 showed a strong birefringence under polarized optical microscopy (Figure $4 \mathrm{~b}$, insets). This is also clear from the lack of transparency of the bulk substances under daylight, indicating light scattering owing to their supramolecularly assembled crystalline domains. It is not yet clear whether polyfluorene can be amorphized and what the minimum structural requirements are. Five-membered thiophene has a low rotational barrier around the carbon bond that bridges the allyl ring and is expected to be further amorphized. ${ }^{41}$ In fact, the more thiophene-rich copolymer 39 exhibited no birefringence.

\subsection{Effect of Side Chain Length ${ }^{63}$}

It is easy to predict that $G^{\prime}$ can be decreased if the side chain length is increased. However, no systematic studies have been conducted so far. We investigated the effect of the side chain length on narrow band gap polymers using dialkoxyphenylene as an internal plasticizer (40-43) (Figure 5). In this polymer design, the internal plasticizer (i.e., Guerbet chains) can be introduced into the dibromobenzene monomer by conventional Williamson ether synthesis. With the shortest 2-ethylhexyl group (40), the polymer exhibited glass-like viscoelasticity with a $G^{\prime}$ of $10^{8}$ Pa due to the polymer having a $T_{\mathrm{g}}$ near room temperature. Despite a slight elongation of the side chain, a 2-butyloctyl group-bearing polymer (41) was observed to have a drastic $T_{\mathrm{g}}$ reduction of approximately $30^{\circ} \mathrm{C}$ and a $G^{\prime}$ reduction of 2 orders of magnitude. Further extension of the side chain (42, 43) achieved a low $G^{\prime}$ comparable to that of polyfluorene CPF 35.

\section{Fluidity-Oriented Functions}

As mentioned at the end of the Introduction section, Type III liquid CPs have insufficient electrical conductivity and cannot be expected to have the optoelectronic 

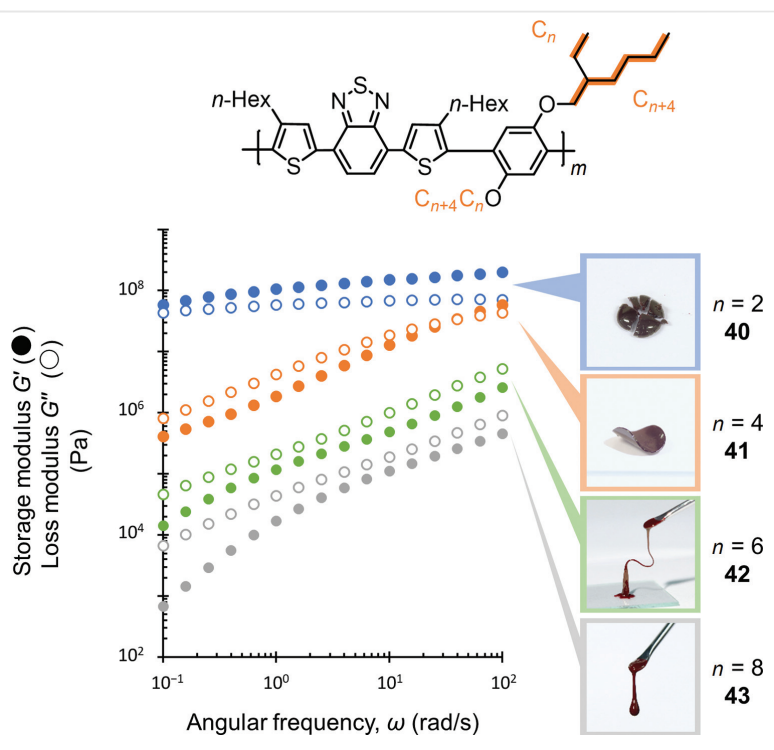

Figure 5 Linear rheological spectra of $\mathbf{4 0 - 4 3}$ at $25^{\circ} \mathrm{C}$. Reprinted with permission from Ref. 63. Copyright 2020 Royal Society of Chemistry.

properties as those of traditional CPs. This section highlights some of the recently discovered 'optical' properties governed by fluidity, which has never been seen in any previous fluidic functional materials.

\subsection{Mechanofluorochromism ${ }^{59}$}

Endowing polymers with unique viscoelasticity-related functions is a fascinating goal. A series of work by Weder and colleagues regarding mechanochromic polymers that can visualize polymer deformation are milestones in this area. $^{64,65}$ It is based on a deformation-induced structural change of the $\pi$-conjugated moiety referred to as the mechanophore. ${ }^{66}$ Basically, this class of mechanochromism is irreversible, because the energy barrier between the initial and final states is too large under ambient conditions. In addition, the crystal dynamics are extremely difficult to predict and control due to their complexity. For this reason, color recovery is a notable property of this class of materials.

We found reversible mechanofluorochromism in a Type III CP blend (Figure 6). A blend of green fluorescent polymer 38 and red fluorescent polymer 39 at a weight ratio of 1:1 exhibited orange fluorescence, but emitted a red color when mechanical stimuli such as scratches were applied. Observation with a fluorescence microscope revealed a clear phase-separation structure in the as-prepared sample (Figure 6a-i). That is, each polymer excited and emitted independently, and thus the mixed color was observed. On the other hand, the phase-separation structure disappeared in the scratched sample (Figure 6a-ii). It is explained that the efficiency of the excitation energy transfer from $\mathbf{3 8}$ to $\mathbf{3 9}$ (a)
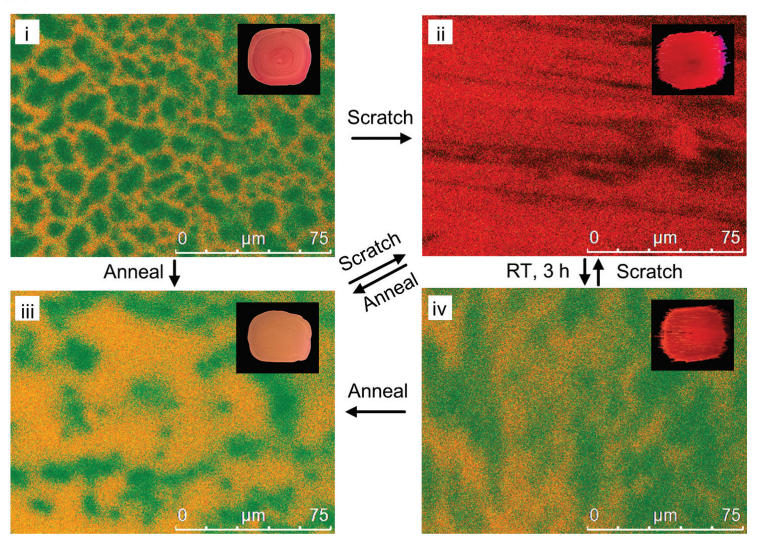

(b)

(c)
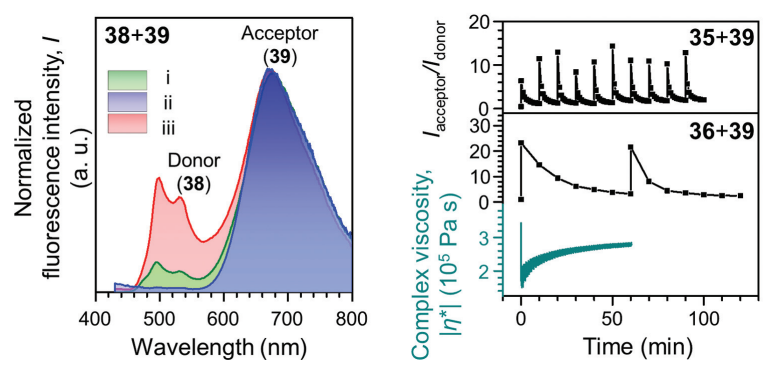

Figure 6 Mechanofluorochromism in Type III CP blends. (a) Fluorescence microscopy images of the binary blend (1:1 w/w) of $\mathbf{3 8}$ (pseudocolor mapped in green) and $\mathbf{3 9}$ (in red); i) as-cast film from dichloromethane, ii) scratched, iii) annealed for $1 \mathrm{~h}$ at $100^{\circ} \mathrm{C}$, and iv) scratched film after $3 \mathrm{~h}$ at room temperature (RT). Insets show photos of films under UV light (365 nm). b) Fluorescence spectra. c) Time course of $I_{\text {acceptor }} / I_{\text {donor }}$ in $\mathbf{3 5}+\mathbf{3 9}$ and $\mathbf{3 6}+\mathbf{3 9}$ blends. The complex viscosity $\left(\left|\eta^{*}\right|\right)$ of the $\mathbf{3 6}+\mathbf{3 9}$ blend after shear deformation showed a virtual mirror image relationship with $I_{\text {acceptor }} / I_{\text {donor }}$. Reprinted with permission from Ref. 59. Copyright 2019 John Wiley.

improves with the enhanced miscibility. Various photochemical experiments support this phenomenon (Figure 6b). If the scratched sample is left at room temperature, phase separation (viscoelastic phase separation) occurs again and the emission color is restored (Figure 6a-iv). None of the polymers are fluids $\left(G^{\prime} \sim 10^{7} \mathrm{~Pa}\right)$, but their $G^{\prime}$ seems to be low enough for phase separation to occur.

Since the rate of phase separation depends on $G^{\prime},{ }^{67}$ the recovery rate of the luminescent color can be controlled by the viscoelasticity. We blended red luminescent polymer $\mathbf{3 9}$ with $50 \mathrm{wt} \%$ of blue luminescent polymers $\mathbf{3 5}$ and $\mathbf{3 6}$ with different $G^{\prime}$, respectively (Figure $6 c$ ). Blending with a fluid polymer $(35+39)$ showed a rapid ( $\sim 10 \mathrm{~min})$ recovery of the luminescent color after scratching, while blending with a rubbery polymer $(\mathbf{3 6}+\mathbf{3 9})$ showed a somewhat longer recovery period $(\sim 1 \mathrm{~h})$. Due to the lack of mixing entropy, the polymers were mostly immiscible. This 
mechanofluorochromism is (i) based on dynamic phase separation, (ii) does not require any special mechanophore design, and (iii) can be achieved by simply mixing two polymers with different bandgaps. This new mechanofluorochromism principle can help simplify the design of future mechanochromic materials.

\subsection{Consistent Luminescence in Wide Range of Elastic}

\section{Moduli ${ }^{63}$}

The intrinsic optical properties of molecules are generally characterized in dilute solutions. Since $\pi$-conjugated molecules have strong intermolecular interactions, aggregation occurs in high-concentration solutions. In such an aggregated state, the optical properties are no longer equivalent due to the planarization of the $\pi$-plane, excimer formation, exciton coupling, etc. Therefore, it is extremely difficult to predict the optical characteristics in the solventfree state, which is the condition in which most polymers are used. Several fluid $\pi$-conjugated small molecules reported so far are known to have the same optical properties as those of dilute solutions. ${ }^{1-9}$ However, it was not clear whether this consistency of optical properties could be maintained in the CP solid and fluid states, or in the rubber state in between.

CPs 40-43, with their wide range of $G^{\prime}$, exhibited consistent fluorescent colors in the fluid, rubber, and even glassy solid states (Figure 7). This suggests that there are no active intermolecular interactions that affect the optical properties of these polymers. It is particularly noteworthy that the optical properties of the glassy polymer $\mathbf{4 0}$ were
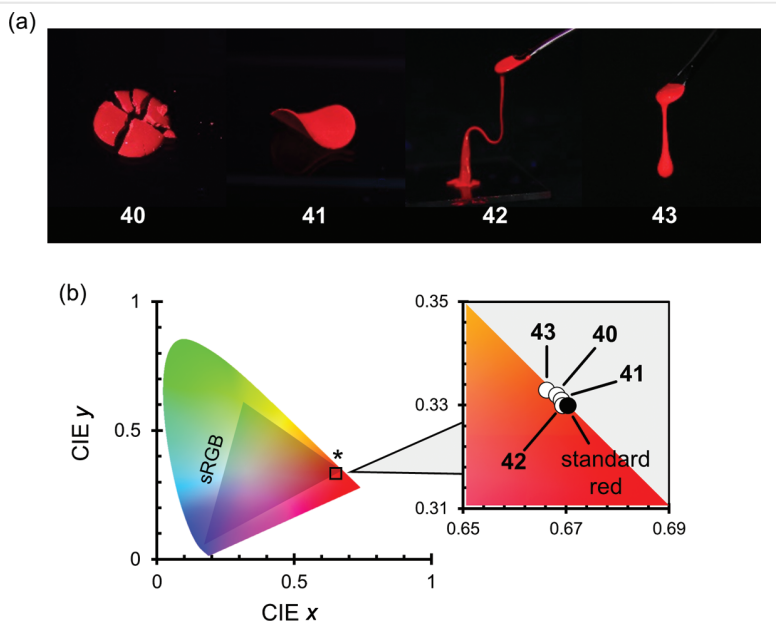

Figure 7 (a) Photos of solvent-free samples of 40-43 under UV light $(365 \mathrm{~nm})$, at room temperature. (b) Emission color chromaticity coordinates on CIE 1931 color space. Standard red: $(x, y)=(0.67,0.33)$. Reprinted with permission from Ref. 63. Copyright 2020 Royal Society of Chemistry. maintained. It is expected that this feature was brought about by amorphous vitrification, but its structural requirements are not yet clear.

\subsection{Prediction of Viscoelasticity ${ }^{63}$}

The viscoelasticity of a polymer, or the deformation dynamics, includes the molecular weight of the polymer, the stiffness of the chains, and the friction coefficient between the polymer chains. This complexity is the reason why predicting the viscoelasticity of the polymers is still challenging, ${ }^{68}$ in other words, precisely designing polymers with the desired viscoelasticity for the purpose.

We found that the glassy polymer $\mathbf{4 0}$ and the fluid polymer $\mathbf{4 3}$ were miscible at all mixing ratios as confirmed by differential scanning calorimetry and modulus mapping mode atomic force microscopy. Therefore, their blends were able to tune the viscoelasticity (Figure 8a). Interestingly, the rheological spectra of the pure polymers and their blends
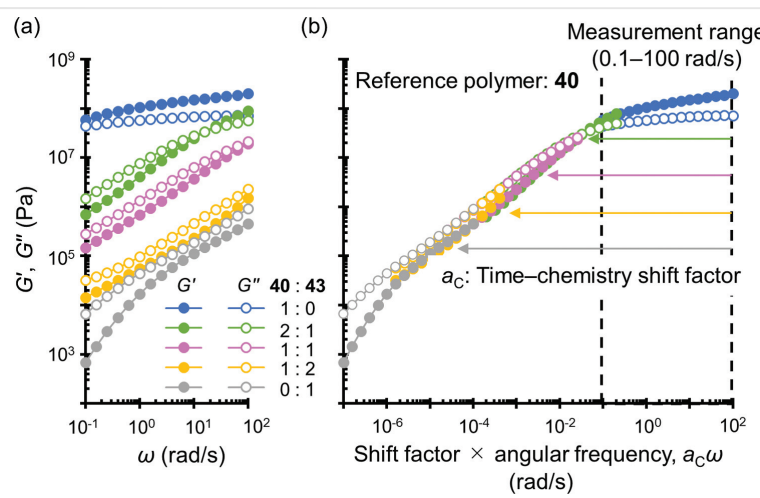

Figure 8 (a) Linear rheological spectra of binary blends $\mathbf{4 0}+\mathbf{4 3}$ with different ratios. (b) Frequency shifted spectra gave a 'master curve' indicating the equivalence between the deformation dynamics and chemical structure. The spectra were referenced to 40 . Reprinted with permission from Ref. 63. Copyright 2020 Royal Society of Chemistry.

obtained a 'master curve' only by frequency shift factors (Figure 8b). Creating a master curve is usually performed on a temperature-dependent spectrum, known as the timetemperature superposition law. ${ }^{69}$ This fact suggests that there is some equivalence between the chemical structure and the polymer dynamics.

In general, the side chain structure of grafted polymers has a great impact on the main chain dynamics. ${ }^{70}$ On the other hand, Type III CP seems to share the same deformation dynamics as liquid polymers (i.e., polymer 40), even in glassy polymers (43). The findings from these electrically inert polymers would be useful in the future for a retroactive understanding of the mechanical properties of 
optoelectronically active CPs. Detailed follow-up work is currently in progress on this anomalous chemical structure-viscoelasticity correlation.

\section{Conclusions and Outlook}

In this short review, we discussed Type III CPs that were fluidified at room temperature with only small molecular side chains. Materials in this class have a short history of research and have not yet been fully elucidated. Therefore, we raise several issues as described below.

First, little is known about the effect of molecular weight on the mechanical properties of CPs, although it is important to better understand the structure-viscoelasticity correlation. In the conventional step-growth approach using cross-coupling reactions, it is essentially impossible to control the molecular weight. Therefore, the introduction of chain growth (living) polymerization is important. ${ }^{71-74}$ In addition to controlling the molecular weight, the living polymerization method has the advantage of obtaining polymers with a narrow molecular weight distribution. The catalyst transfer polymerization method has recently attracted attention as a living polymerization method to obtain well-defined CPs. Using this method, polythiophene, polyfluorene, polyphenylene, etc. are being actively studied. In addition, various alternating copolymers can be obtained by using dimeric monomers. ${ }^{75}$ Living anionic polymerization in PPV is also a well-known method. ${ }^{53}$ In addition, there are many reports on the synthesis of PPV using the ring-opening metathesis polymerization method. ${ }^{76,77}$ The living polymerization of CPs is still poorly substrate-tolerant and leaves much room for research.

We have prioritized to fluidify CPs rather than optimization of their electrical properties. However, balancing the softness and the electrical properties is one of our goals. Based on the existing knowledge, assembled structures in a supramolecular manner are the least requirement to possess sufficient electrical conductivity. This is classified as Type II, but can be achieved by morphology control such as by utilizing block copolymers. Proper combination of Type I-III approaches appears to be important.

In order to take full advantage of the properties of functional fluid materials such as CPFs, it is necessary to devise new device manufacturing methods, geometries, and working principles rather than replacing the active materials of existing devices. For example, fluidic active material can be loaded into the device just by soaking, as we proposed recently for the stretchable electric generator. ${ }^{1}$ Encouraging works of Adachi et al. ${ }^{78}$ and Mizuno et al. ${ }^{79}$ are for unprecedented 'refillable' electroluminescent devices using fluid convection and microinjection, which demonstrates well the characteristics of a fluid.
The functions of the $\pi$-conjugated units are highly diversified. Not limited to electrical characteristics, the various functions expected of a $\pi$-conjugated unit can be given to viscoelastic CPs. Light absorption/emission, electron spin, and photosensitization are just some of the many possibilities. It is expected that numerous highly functional polymer fluids will appear in the future.

\section{Funding Information}

This study was supported by Grants-in-Aid for Scientific Research (JSPS KAKENHI Grant Number JP18H03922).

\section{References}

(1) Ghosh, A.; Yoshida, M.; Suemori, K.; Isago, H.; Kobayashi, N.; Mizutani, Y.; Kurashige, Y.; Kawamura, I.; Nirei, M.; Yamamuro, O.; Takaya, T.; Iwata, K.; Saeki, A.; Nagura, K.; Ishihara, S.; Nakanishi, T. Nat. Commun. 2019, 10, 4210.

(2) Michinobu, T.; Nakanishi, T.; Hill, J. P.; Funahashi, M.; Ariga, K. J. Am. Chem. Soc. 2006, 128, 10384.

(3) Hollamby, M. J.; Karny, M.; Bomans, P. H. H.; Sommerdijk, N. A.; Saeki, A.; Seki, S.; Minamikawa, H.; Grillo, I.; Pauw, B. R.; Brown, P.; Eastoe, J.; Möhwald, H.; Nakanishi, T. Nat. Chem. 2014, 6, 690.

(4) Lu, F.; Jang, K.; Osica, I.; Hagiwara, K.; Yoshizawa, M.; Ishii, M.; Chino, Y.; Ohta, K.; Ludwichowska, K.; Kurzydłowski, K. J.; Ishihara, S.; Nakanishi, T. Chem. Sci. 2018, 9, 6774.

(5) Babu, S. S.; Aimi, J.; Ozawa, H.; Shirahata, N.; Saeki, A.; Seki, S.; Ajayaghosh, A.; Möhwald, H.; Nakanishi, T. Angew. Chem. 2012 124, 3447; Angew. Chem. Int. Ed. 2012, 51, 3391.

(6) Babu, S. S.; Hollamby, M. J.; Aimi, J.; Ozawa, H.; Saeki, A.; Seki, S.; Kobayashi, K.; Hagiwara, K.; Yoshizawa, M.; Möhwald, H.; Nakanishi, T. Nat. Commun. 2013, 4, 1969.

(7) Zielinska, A.; Takai, A.; Sakurai, H.; Saeki, A.; Leonowicz, M.; Nakanishi, T. Chem. Asian J. 2018, 13, 770.

(8) Narayan, B.; Nagura, K.; Takaya, T.; Iwata, K.; Shinohara, A.; Shinmori, H.; Wang, H.; Li, Q.; Sun, X.; Li, H.; Ishihara, S.; Nakanishi, T. Phys. Chem. Chem. Phys. 2018, 20, 2970.

(9) Lu, F.; Takaya, T.; Iwata, K.; Kawamura, I.; Saeki, A.; Ishii, M.; Nagura, K.; Nakanishi, T. Sci. Rep. 2017, 7, 3416.

(10) Duan, P.; Yanai, N.; Kimizuka, N. J. Am. Chem. Soc. 2013, 135, 19056.

(11) Kushwaha, K.; Yu, L.; Stranius, K.; Singh, S. K.; Hultmark, S.; Iqbal, M. N.; Eriksson, L.; Johnston, E.; Erhart, P.; Müller, C.; Börjesson, K. Adv. Sci. 2019, 6, 1801650.

(12) Adachi, N.; Itagaki, R.; Sugeno, M.; Norioka, T. Chem. Lett. 2014, 43, 1770.

(13) Ishi-i, T.; Sakai, M.; Shinoda, C. Tetrahedron 2013, 69, 9475.

(14) Allain, C.; Piard, J.; Brosseau, A.; Han, M.; Paquier, J.; Marchandier, T.; Lequeux, M.; Boissière, C.; Audebert, P. ACS Appl. Mater. Interfaces 2016, 8, 19843.

(15) Machida, T.; Taniguchi, R.; Oura, T.; Sada, K.; Kokado, K. Chem. Commun. 2017, 53, 2378.

(16) Enozawa, H.; Ukai, S.; Ito, H.; Murata, T.; Morita, Y. Org. Lett. 2019, 21, 2161.

(17) Ogoshi, T.; Maruyama, K.; Sakatsume, Y.; Kakuta, T.; Yamagishi, T. A.; Ichikawa, T.; Mizuno, M. J. Am. Chem. Soc. 2019, 141, 785. 
(18) Giri, N.; Del Pópolo, M. G.; Melaugh, G.; Greenaway, R. L.; Rätzke, K.; Koschine, T.; Pison, L.; Gomes, M. F.; Cooper, A. I.; James, S. L. Nature 2015, 527, 216.

(19) Rodrigues, D.; Sarmiento, G. P.; Krimer, N. I.; Mirenda, M. ACS Appl. Electron. Mater. 2020, 2, 2662.

(20) Isoda, K.; Ishiyama, T.; Mutoh, Y.; Matsukuma, D. ACS Appl. Mater. Interfaces 2019, 11, 12053.

(21) Walsh, J. C.; Hogan, D. T.; Williams, K. M.; Brake, S. D.; Venkataramana, G.; Misener, T. A.; Wallace, B. J.; Johnson, R. P.; Thompson, D. W.; Zhao, Y.; Wagner, B. D.; Bodwell, G. J. ChemPlusChem 2019, 84, 754.

(22) Norikane, Y.; Hirai, Y.; Yoshida, M. Chem. Commun. 2011, 47, 1770.

(23) Hendrickx, E.; Guenther, B. D.; Zhang, Y.; Wang, J. F.; Staub, K.; Zhang, Q.; Marder, S. R.; Kippelen, B.; Peyghambarian, N. Chem. Phys. 1999, 245, 407.

(24) Joo, J.; Long, S. Phys. Rev. B: Condens. Matter 1998, 57, 9567.

(25) Chiang, C. K.; Fincher, C. R.; Park, Y. W.; Heeger, A. J.; Shirakawa, H.; Louis, E. J.; Gau, S. C.; MacDiarmid, A. G. Phys. Rev. Lett. 1977, 39, 1098.

(26) Rubinstein, M.; Colby, R. H. Polymer Physics. Oxford University Press: Oxford, 2003.

(27) Savagatrup, S.; Zhao, X.; Chan, E.; Mei, J.; Lipomi, D. J. Macromol. Rapid Commun. 2016, 37, 1623.

(28) Oh, J. Y.; Rondeau-Gagné, S.; Chiu, Y. C.; Chortos, A.; Lissel, F.; Wang, G. N.; Schroeder, B. C.; Kurosawa, T.; Lopez, J.; Katsumata, T.; Xu, J.; Zhu, C.; Gu, X.; Bae, W. G.; Kim, Y.; Jin, L.; Chung, J. W.; Tok, J. B. H.; Bao, Z. Nature 2016, 539, 411.

(29) Baek, P.; Mata, J. P.; Sokolova, A.; Nelson, A.; Aydemir, N.; Shahlori, R.; McGillivray, D. J.; Barker, D.; Travas-Sejdic, J. Soft Matter 2018, 14, 6875.

(30) Baek, P.; Kerr-Phillips, T.; Damavandi, M.; Chaudhary, O. J.; Malmstrom, J.; Chan, E. W. C.; Shaw, P.; Burn, P.; Barker, D.; Travas-Sejdic, J. Eur. Polym. J. 2016, 84, 355.

(31) Baek, P.; Aydemir, N.; An, Y.; Chan, E. W. C.; Sokolova, A.; Nelson, A.; Mata, J. P.; McGillivray, D.; Barker, D.; Travas-Sejdic, J. Chem. Mater. 2017, 29, 8850.

(32) Baek, P.; Voorhaar, L.; Barker, D.; Travas-Sejdic, J. Acc. Chem. Res. 2018, 51, 1581.

(33) Zokaei, S.; Kroon, R.; Gladisch, J.; Paulsen, B. D.; Sohn, W.; Hofmann, A. I.; Persson, G.; Stamm, A.; Syrén, P.; Olsson, E.; Rivnay, J.; Stavrinidou, E.; Lund, A.; Müller, C. Adv. Sci. 2021, 8, 2002778.

(34) Chiang, Y. C.; Kobayashi, S.; Isono, T.; Shih, C. C.; Shingu, T.; Hung, C. C.; Hsieh, H. C.; Tung, S. H.; Satoh, T.; Chen, W. C. Polym. Chem. 2019, 10, 5452.

(35) Podzorov, V. Nat. Mater. 2013, 12, 947.

(36) Qian, Z.; Cao, Z.; Galuska, L.; Zhang, S.; Xu, J.; Gu, X. Macromol. Chem. Phys. 2019, 220, 1900062.

(37) Wang, M.; Baek, P.; Akbarinejad, A.; Barker, D.; Travas-Sejdic, J. J. Mater. Chem. C 2019, 7, 5534.

(38) Xie, R.; Lee, Y.; Aplan, M. P.; Caggiano, N. J.; Müller, C.; Colby, R. H.; Gomez, E. D. Macromolecules 2017, 50, 5146.

(39) Edgeworth, R.; Dalton, B. J.; Parnell, T. Eur. J. Phys. 1984, 5, 198.

(40) Pankaj, S.; Beiner, M. J. Phys. Chem. B 2010, 114, 15459.

(41) Xie, R.; Weisen, A. R.; Lee, Y.; Aplan, M. A.; Fenton, A. M.; Masucci, A. E.; Kempe, F.; Sommer, M.; Pester, C. W.; Colby, R. H.; Gomez, E. D. Nat. Commun. 2020, 11, 893.

(42) Yu, L.; Davidson, E.; Sharma, A.; Andersson, M. R.; Segalman, R.; Müller, C. Chem. Mater. 2017, 29, 5654.
(43) Lu, C.; Lee, W. Y.; Gu, X.; Xu, J.; Chou, H. H.; Yan, H.; Chiu, Y. C.; He, M.; Matthews, J. R.; Niu, W.; Tok, J. B. H.; Toney, M. F.; Chen, W. C.; Bao, Z. Adv. Electron. Mater. 2017, 3, 1600311.

(44) Zhang, S.; Ocheje, M. U.; Huang, L.; Galuska, L.; Cao, Z.; Luo, S.; Cheng, Y. H.; Ehlenberg, D.; Goodman, R. B.; Zhou, D.; Liu, Y.; Chiu, Y. C.; Azoulay, J. D.; Rondeau-Gagné, S.; Gu, X. Adv. Electron. Mater. 2019, 5, 1800899.

(45) Zhang, S.; Ocheje, M. U.; Luo, S.; Ehlenberg, D.; Appleby, B.; Weller, D.; Zhou, D.; Rondeau-Gagné, S.; Gu, X. Macromol. Rapid Commun. 2018, 39, 1800092.

(46) Li, Y.; Tatum, W. K.; Onorato, J. W.; Zhang, Y.; Luscombe, C. K. Macromolecules 2018, 51, 6352.

(47) Sommerville, P. J. W.; Li, Y.; Dong, B. X.; Zhang, Y.; Onorato, J. W.; Tatum, W. K.; Balzer, A. H.; Stingelin, N.; Patel, S. N.; Nealey, P. F.; Luscombe, C. K. Macromolecules 2020, 53, 7511.

(48) Jin, Y. J.; Bae, J. E.; Cho, K. S.; Lee, W. E.; Hwang, D. Y.; Kwak, G. Adv. Funct. Mater. 2014, 24, 1928.

(49) Jin, Y. J.; Yoon, J. H.; Sakaguchi, T.; Lee, C. L.; Kwak, G. Adv. Funct. Mater. 2016, 26, 4501.

(50) Jin, Y. J.; Kawamura, Y.; Teraguchi, M.; Aoki, T.; Kwak, G. Polymer 2017, 123, 81.

(51) Vandenbergh, J.; Van Severen, I.; Lutsen, L.; Adriaensens, P.; Bolink, H. J.; Cleij, T. J.; Vanderzande, D. Polym. Chem. 2011, 2, 1279.

(52) Jin, Y.; Kim, J. Y.; Song, S.; Xia, Y.; Kim, J.; Woo, H. Y.; Lee, K.; Suh, H. Polymer 2008, 49, 467.

(53) Zaquen, N.; Lutsen, L.; Vanderzande, D.; Junkers, T. Polym. Chem. 2016, 7, 1355.

(54) Zhao, J.; Bertho, S.; Vandenbergh, J.; Van Assche, G.; Manca, J.; Vanderzande, D.; Yin, X.; Shi, J.; Cleij, T.; Lutsen, L.; Van Mele, B. Phys. Chem. Chem. Phys. 2011, 13, 12285.

(55) Kim, J. Y.; Frisbie, C. D. J. Phys. Chem. C 2008, 112, 17726.

(56) Seehafer, K.; Bender, M.; Schwaebel, S. T.; Bunz, U. H. F. Macromolecules 2014, 47, 7014.

(57) Ribierre, J. C.; Zhao, L.; Inoue, M.; Schwartz, P. O.; Kim, J. H.; Yoshida, K.; Sandanayaka, A. S. D.; Nakanotani, H.; Mager, L.; Méry, S.; Adachi, C. Chem. Commun. 2016, 52, 3103.

(58) Maya, E. M.; Shirk, J. S.; Snow, A. W.; Roberts, G. L. Chem. Commun. 2001, 615.

(59) Shinohara, A.; Pan, C.; Guo, Z.; Zhou, L.; Liu, Z.; Du, L.; Yan, Z.; Stadler, F. J.; Wang, L.; Nakanishi, T. Angew. Chem. 2019, 131, 9682; Angew. Chem. Int. Ed. 2019, 58, 9581.

(60) Hollamby, M. J.; Nakanishi, T. J. Mater. Chem. C 2013, 1, 6178.

(61) Papadopoulos, P.; Floudas, G.; Chi, C.; Wegner, G. J. Chem. Phys. 2004, 120, 2368.

(62) Winter, H. H. In Structure and Dynamics of Polymer and Colloidal Systems. Borsali, R.; Pecora, R. Springer Netherlands: Dordrecht, 2002, 439.

(63) Guo, Z.; Shinohara, A.; Pan, C.; Stadler, F. J.; Liu, Z.; Yan, Z.; Zhao, J.; Wang, L.; Nakanishi, T. Mater. Horiz. 2020, 7, 1421.

(64) Crenshaw, B. R.; Weder, C. Chem. Mater. 2003, 15, 4717.

(65) Sagara, Y.; Karman, M.; Verde-Sesto, E.; Matsuo, K.; Kim, Y.; Tamaoki, N.; Weder, C. J. Am. Chem. Soc. 2018, 140, 1584.

(66) Willis-Fox, N.; Rognin, E.; Aljohani, T. A.; Daly, R. Chem 2018, 4, 2499.

(67) Tanaka, H. Phys. Rev. E: Stat. Phys. Plasmas Fluids Relat. Interdiscip. Top. 1997, 56, 4451.

(68) Ramprasad, R.; Batra, R.; Pilania, G.; Mannodi-Kanakkithodi, A.; Kim, C. Npj Comput. Mater. 2017, 3, 54.

(69) Urzhumtsev, Y. S. Polym. Mech. 1975, 11, 57. 
Organic Materials

A. Shinohara et al.

Short Review

(70) Daniel, W. F. M.; Burdyńska, J.; Vatankhah-Varnoosfaderani, M.; Matyjaszewski, K.; Paturej, J.; Rubinstein, M.; Dobrynin, A. V.; Sheiko, S. S. Nat. Mater. 2016, 15, 183.

(71) Leone, A. K.; McNeil, A. J. Acc. Chem. Res. 2016, 49, 2822.

(72) Aplan, M. P.; Gomez, E. D. Ind. Eng. Chem. Res. 2017, 56, 7888.

(73) Verheyen, L.; Leysen, P.; Van Den Eede, M. P.; Ceunen, W.; Hardeman, T.; Koeckelberghs, G. Polymer 2017, 108, 521.

(74) Yokozawa, T.; Ohta, Y. Chem. Commun. 2013, 49, 8281.

(75) Ono, R.J.; Kang, S.; Bielawski, C. W. Macromolecules 2012, 45, 2321.

(76) Conticello, V. P.; Gin, D. L.; Grubbs, R. H. J. Am. Chem. Soc. 1992, $114,9708$.

(77) Elacqua, E.; Gregor, M. Angew. Chem. 2019, 131, 9627; Angew. Chem. Int. Ed. 2019, 58, 9527.

(78) Shim, C.; Hirata, S.; Oshima, J.; Edura, T.; Hattori, R.; Adachi, C. Appl. Phys. Lett. 2012, 101, 113302.

(79) Kawamura, M.; Kuwae, H.; Kamibayashi, T.; Oshima, J.; Kasahara, T.; Shoji, S.; Mizuno, J. Sci. Rep. 2020, 10, 14528. 